\title{
Training for reproductive health: Beyond apprenticeship
}

\author{
Lindsay Edouard, FRCOG, MFFP, International Advisor, Journal of Family Planning and Reproductive Health Care
}

The need for training in family planning to move away from an apprentice system to a more formal modality with a broad perspective on the discipline was given much consideration in the middle of the 1970 s. ${ }^{1}$ The specialty of obstetrics and gynaecology had been primarily surgical until developments in gynaecological endocrinology and family planning had a substantial impact on service provision. From the 1960s, questions on contraception were included in the examinations for the diploma and membership of the Royal College of Obstetricians and Gynaecologists (RCOG) and from 1975, candidates had to attend family planning clinics as part of their training. ${ }^{2}$ The name of the official publication of the National Association of Family Planning Doctors (NAFPD) changed from the Journal of Family Planning Doctors to the British Journal of Family Planning in April 1977, that title being used until October 2000. In 1977, the contents of the Journal went far beyond contraception, with articles addressing a wide range of topics during that year: female sexuality, psychosexual medicine, promiscuity, male attitudes, pregnancy advice, menopause, rubella, infertility and culture.

The Joint Committee on Contraception (JCC) was established by the RCOG and the Royal College of General Practitioners in 1972 with NAFPD joining in 1975. The JCC set standards for training and the competency of service providers, its certificate stating that the holder 'has special experience and competence in the techniques of contraception and family planning'. Various organisations, such as the Family Planning Association and academic departments, held theoretical courses as attendance was needed to meet requirements for JCC certification besides practical training, regulations stipulating the clinical procedures to be carried out. As general practitioners offered integrated services, ${ }^{3}$ the special circumstances of those who had provided services for a long time, albeit without JCC certification, were recognised. ${ }^{4}$

Family planning was already being perceived in a wide context to the extent that the teaching of sexuality was becoming increasingly common in the undergraduate curriculum of British medical schools. 5 This approach reflected the coming of age of a new specialty with its multifaceted components and away from the former image of isolated tasks in the hands of the bold surgeon with a sharp knife.

Official recognition of reproductive health as a specialty occurred when the Faculty of Family Planning and Reproductive Health Care (FFPRHC) was established within the RCOG in 1993. The FFPRHC now sets the content and monitors standards for the theoretical and practical training components for its diploma (DFFP) to meet the changing needs of delivering sexual and reproductive health services within primary medical care. As part of clinical governance, the Faculty manages a programme for the continuing professional development and re-certification of medical practitioners. It also holds its membership (MFFP) examinations with structured training and assessment in accredited centres; a 3-year programme for non-consultant, career-grade doctors and a 5-year programme for consultant training. With the trend towards further specialisation, the RCOG acknowledged the increasing importance of sexual and reproductive health by establishing a joint training committee with the FFPRHC to address the subspecialty training requirements. This committee is developing a comprehensive syllabus, content and organisation of subspecialty training in sexual and reproductive health.

Finally, at an undergraduate and international level, there is a very interesting initiative of the Commonwealth Medical Association Trust, ${ }^{6}$ which is promoting the integration of sexual and reproductive health in the curriculum of medical schools. We shall watch with interest the impact of this approach on the specialty over the next 25 years.

References

1 Editorial. Reflections on a conference. Br J Fam Plann 1977; 3: 42.

2 Pollock M, Gregson E. The Bristol conference. Br J Fam Plann 1977; 3: 45-46.

3 Potts M. The GP in a fully integrated family planning service. $B r J$ Fam Plann 1977; 3: 4.

4 Hooper P. GPs and evidence to the Royal Commission on the NHS. $\mathrm{Br}$ J Fam Plann 1977; 3: 23.

5 Stanley E. A course in human sexuality for medical students at St George's Hospital. Br J Fam Plann 1977; 3: 16-17.

6 Commonwealth Medical Association Trust. Sexual and reproductive health in the medical curriculum - Report of an expert consultation held at the Royal College of Obstetricians and Gynaecologists, London, 21-24 March 2001. London: Commonwealth Medical Association Trust, 2001.

\section{Journal of Family Planning and Reproductive Health Care}

\section{TRAINEE EDITOR POST}

$$
\text { January-December } 2003
$$

\section{Applications are invited for this innovative 1-year post}

Are you an SpR or Career Grade Trainee who would be interested in learning about the editorial process and participate in the production of the Bulletin Board and Journal Club?

\author{
For further information and a job description \\ please contact: \\ Jacquie Silcott, Journal Administrator, \\ Faculty of Family Planning and \\ Reproductive Health Care, \\ 19 Cornwall Terrace, \\ London NW1 4QP, UK. \\ Tel: +44 (0) 2079357162 . \\ Fax: +44 (0) 2079358613 . \\ E-mail: journal@ffprhc.org.uk
}

Closing date: 8.11 .02

Interviews will be held in Sheffield on 21.11.02

(to coincide with the Current Choices Meeting) 